\title{
Discussion on Quality Control of Drilling Lotion
}

\author{
Inner Mongolia Autonomous Region Second Geological and Mineral Exploration and Development Institute Inner \\ Mongolia 015000
}

\section{Introduction}

The rinse solution plays an important role in the drilling engineering. Due to the lack of professional and technical training of the domestic geological drilling team and the lack of professional and technical training, the drilling and washing fluid has not been given enough attention. The construction of the rinse solution is chaotic, too much to pursue the surface of the economic interests of the drilling fluid is not on the various aspects of effective quality control. Resulting in the lack of professional technicians in the drilling project, the lack of equipment and equipment and improve the rinse management system, to some extent caused by drilling quality, efficiency, cost increases, or drilling difficult to continue drilling difficulties. After years of scientific research and development, the flushing liquid additive has been from drilling only to meet the development of drilling to meet the needs of all the drilling fluid system. For example: low-viscosity, low-friction, low-solids polymer rinse for rapid drilling services. Anti-card rinses liquid, for the rock characteristics of the anti-collapse rinse solution, drilling salt layer of saturated brine rinse liquid, to form a complete flushing system. However, in recent years, the development, use and management of the rinse liquid in the construction of the drilling engineering are relatively extensive, which need to change the status quo of the drilling technology construction technology, improve the quality control of this important part of the rinse solution, enhance the construction quality, Thus laying a foundation for solving the complex problems of drilling engineering.

\section{Drilling rinse liquid quality control problems}

Due to the change of the management system, the drilling engineering management work weakened, and the quality management and control of the drilling rinse liquid appeared serious regression phenomenon. Appears in:

1.1 Lack of understanding of the guiding ideology. Drilling construction operators, only to see the quality of washing fluid, strict control will bring materials, labor costs increase, do not pay attention to reduce the hole accident, improve drilling efficiency, reduce drill pipe wear and other comprehensive technical benefits.

1.2 Serious lack of professional and technical personnel. Machine operators to explore their own and old and new workers to help pass. Including the lack of leadership and demonstration teams across the industry.

1.3 The device is not configured and the test equipment is missing. At present, most of the machine is not equipped with test equipment, rinse solution design lack of scientific, rinse solution design and actual performance indicators far.

1.4 On-site washing fluid quality control is extremely low. The machine rinse liquid management does not set the post, the scene does not test the performance

\begin{abstract}
Drilling fluid is an important technology in drilling engineering in drilling engineering. However, due to the influence of domestic geological drilling, the drilling fluid has not been given enough attention, and there is a shortage of professional technicians and equipment in the construction process. , rinse formula clutter, the lack of the formation of targeted and other issues, resulting in low-efficiency drilling, hole accidents frequently. Based on the characteristics and principles of the quality control of each part of the drilling fluid, the quality control, system composition and how to ensure the quality of the rinse solution are explored in detail. It is hoped that the quality control of the rinse solution will have some value and significance.
\end{abstract}

Key words: Drilling washing liquid; Quality control; Characteristic; Principle; System

Published online: 15th July, 2017

of the rinse fluid, do not use the rinse liquid purification equipment, sometimes, the scene rinses circulation system cannot meet the requirements.

The existence of these problems, the drilling production caused a great impact, hole accidents, long stay, low efficiency, poor 
drilling quality, must be addressed.

\section{Characteristics and Principles of Quality Control of Drilling Flu- id}

2.1 Drilling fluid quality control features

2.1.1 There are many factors that affect the quality control of the rinse solution. The drilling rinsing solution is affected by factors such as the drilling process method, the level of the operator, the equipment for the processing of the rinse solution, the operation process, the type and material of the flushing fluid, the drilling of the formation, the drilling environment and other factors, and all the influencing factors Liquid quality monitoring has a certain degree of impact, some direct impact, and some indirect effects.

2.1.2 Drilling fluid quality control with dynamic and real-time. Drilling fluid quality is changing with the drilling process, is a dynamic process, the need for real-time monitoring and adjustment to maintain a stable design performance; rinse solution is based on drilling technology, known strata, trade-off economic benefits, But the drilling of the formation is a great deal of uncertainty, especially the extent of the formation of the broken, different layers require different performance of the rinse solution, the need for real-time performance of the rinse fluid to adjust, or even re- place.

2.2 Drilling fluid quality control principles

2.2.1 Focus on comprehensive economic benefits. Drilling fluid quality control is designed to maximize the overall economic benefits of drilling production. Appropriate drilling rinses fluid quality control is designed to meet the drilling engineering requirements for the performance of the rinse solution, which is appropriate to require high-tech quality to grasp.

2.2.2 People is the first priority of quality control. People are the main target of maintaining the quality of the rinse fluid, including technicians, operators and managers. The occupational level and professional competence of the various operating personnel have a more or less effect on the quality of the drilling fluid. Therefore, in the quality of drilling fluid inspection, should emphasize the importance of people, control the overall quality of staff, thereby improving the quality of drilling and washing fluid maintenance and control.

2.2.3 Design is the key. The maintenance control of the quality of each part of the drilling fluid should take into account the influencing factors to formulate the comprehensive control measures and the possible countermeasures to deal with the mud quality problems.
2.2.4 Guidelines for the management of drilling mud technology. "Drilling mud technology management approach" is the science and technology and practical experience of the formation of professional and technical management documents.

\section{Quality control measures for each part of the drilling fluid}

3.1 Strengthen management quality control

Drilling fluid on-site management is the basis of quality control of the rinse solution, and the quality of the rinsing liquid is well controlled. Therefore, people are the main object of the quality control of the drilling fluid. All the quality control, if the lack of human implementation and supervision, then, despite the advanced equipment, high-quality materials, it is difficult to protect the quality of construction.

In terms of specific circumstances, people should guide the formation of quality control to the quality of the concept, the implementation of job responsibilities and strengthen the supervision of duties as a starting point. Specific human quality monitoring structure shown in Figure 1 below. (1) Guide the staff to form a rinse liquid quality concept

To this point, should guide the drilling staff to re-understand the performance of the rinse liquid to form an objective view of the quality of

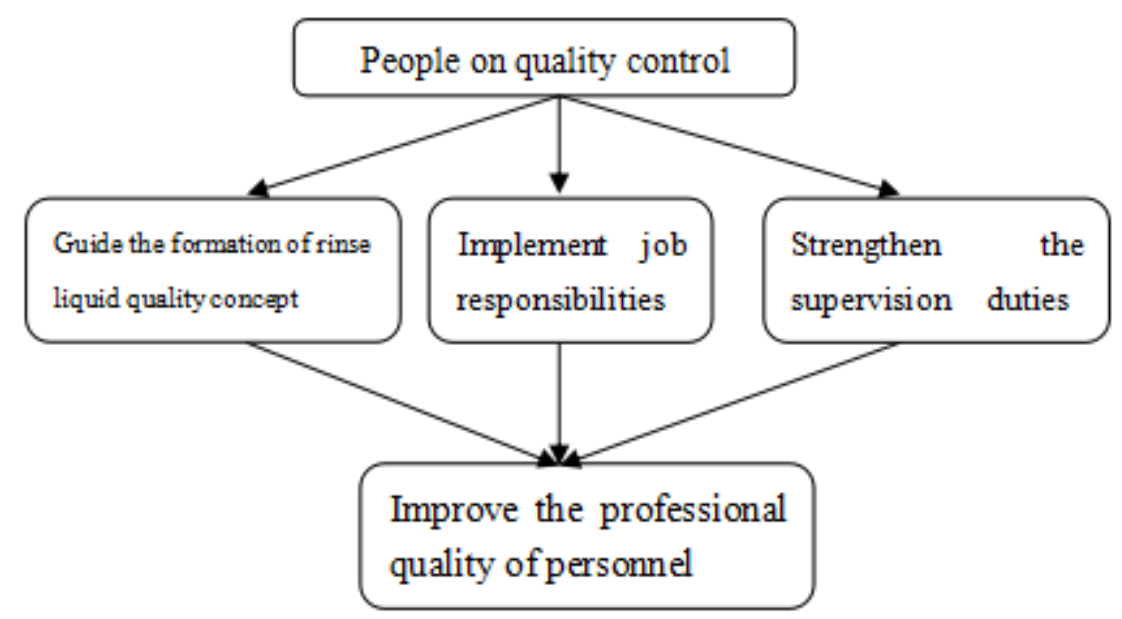

Figure 1 On the quality control monitoring structure 
the mud, the relevant staff should be aware of the rinse solution is a key link in the drilling project. In addition, the quality of the first principle should be through the whole process of drilling, each link is no exception.

(2) Implementation of job responsibilities

In strengthening the quality of drilling operations personnel at the same time, but also to implement their duties, that is, to carry out their duties, the responsibility.

(3) Strengthen the supervision duties

In addition to the implementation of the duties of the drilling staff, but also strengthen the supervision of duties. Although some of the drilling works now stipulate the mud construction duties and supervision standards, but the overall implementation of the situation is not satisfactory, this is due to the supervision work is not effectively carried out. It can be seen, the need to build a drilling mud construction supervision system, the relevant responsible staff on-site inspection, and included in the overall drilling engineering supervision and inspection work.

All in all, people are not part of the quality control of the work should be integrated into the construction of the entire drilling project. To organize the construction staff to participate in quality control training, regular supervision and inspection of the implementation of the duties of the construction staff.

3.2 Quality control of the rinse solution during the construction preparation phase

In the drilling project before the construction of a simple laboratory, with the construction site test equipment. The investigation, digging to understand the geological structure, structure, etc. to determine the type of rinse solution, through the test design rinse formula and preparation methods, processes, to determine the rinse liquid material.

\subsubsection{Quality control of slurry labora- tory formation and management}

It is required to monitor the performance parameters of the rinse liquid in real time, and it is necessary to adjust the performance of the flushing liquid in combination with the actual time. And in the adjustment, before the simulation experiment to determine the effectiveness of the design, so the construction of mud laboratory is necessary. At the same time, the mud laboratory plays a new role in research and development drilling, training drilling personnel and other functions, so the management of its quality control is also necessary.

Site mud detection equipment shown in Table 1, common equipment see Figure 2.

The daily maintenance of instruments and equipment is a key link in laboratory management, designed to ensure the normal operation of equipment and detection accuracy, while increasing the use of equipment and equipment time. It can be seen that the development of laboratory mud equipment, routine maintenance system, the daily maintenance of mud has an important role in maintenance.

\subsubsection{Design quality of rinse solution}

\section{(1) Design basis:}

Drilling fluid design is mainly based on drilling technology (such as: reverse circulation drilling, rope core drilling, foam drilling, hydraulic dive hammer drilling, drilling structure and depth, etc.), stratigraphic geological conditions (such as geology Age, formation stress, rock lithology and cementing degree, formation consistency, thickness, burial depth, porosity and temperature gradient, etc.), protection of ore layer, environmental protection requirements,

\begin{tabular}{|l|l|l|l|}
\hline No & Instrument device name & Quantity & Remark \\
\hline 1 & Density meter (range $<0.2 \mathrm{~g} / \mathrm{cm} 3$ ) (unit) & 2 & \\
\hline 2 & $\begin{array}{l}\text { Fan's funnel viscometer, Markov funnel vis- } \\
\text { cometer (unit) }\end{array}$ & 2 & \\
\hline 3 & Six-speed rotary viscometer (sets) & 1 & \\
\hline 4 & API water loss equipment (unit) & 1 & \\
\hline 5 & Solid content analyzer (unit) & 1 & \\
\hline 6 & Sediment Concentrator (sets) & 1 & \\
\hline 7 & PH meter / test paper (sets) & 1 & \\
\hline 9 & Extreme Pressure Lubricator (sets) & 1 & \\
\hline 10 & Stopwatch (unit) & 2 & Enamel or stainless steel \\
\hline 11 & $2000 \mathrm{ml}$ Drilling liquid cup (unit) & 1 & \\
\hline 12 & High-speed stirrer (sets) & 1 & \\
\hline 13 & Electronic balance (0.1 grams) (unit) & 1 & \\
\hline
\end{tabular}

Table 1 Site mud detection facilities 
circulation system conditions and so on. Are on the type of washing fluid, the performance of the selection of a direct impact. All the conditions should be selected the appropriate rinse solution design.

\section{(2) Design principles}

First, to the geological design, drilling engineering design and other related information, based on the relevant technical specifications, regulations and standards for drilling rinse solution design. The second is to field investigation, as far as possible to collect the impact of drilling safety of the stratigraphic samples. Third, in the analysis of the safety and quality of drilling operations on the basis of efficiency, the development of the appropriate drilling fluid technology measures. Fourth, the design formula through the sample bubble test to choose the best option. Fifth is to find the geological conditions of the formation of the design program cannot meet the needs of drilling operations, immediately test the adjustment program. Sixth is the rinse liquid performance design contradictions, grasp the main issues, taking into account the secondary issues, comprehensive care of the overall performance of the performance requirements of the occasion is not high, appropriate to relax the secondary indicators in order to obtain low cost and high efficiency. Seventh is the material, the treatment agent to seek less varieties, easy to operate, and the most economical.

\section{(3) Design process}

Pre-selected rinse liquid material and treatment agent $\rightarrow$ determine the technical indicators and performance parameters $\rightarrow$ multi-recipe design $\rightarrow$ test comparison $\rightarrow$ determine the preparation method and maintenance, adjustment program $\rightarrow$ to develop the cycle, purification, management measures $\rightarrow$ determine the material and treatment agent $\rightarrow$ drilling application $\rightarrow$ modify Formula, test.

Drilling strata have a lot of uncertainty and cannot be fully foreseen before drilling. Such as rock formation, fault zone, formation gap, cave, etc. changes, need to make timely adjustments to the drilling fluid in order to ensure drilling safety and stability. Only to meet the drilling safety, stability, high-efficiency drilling fluid is qualified drilling rinse.

(4) Quality control of rinse solution formulation test

Strictly in accordance with the test standards for testing;

Stratigraphic samples must be representative of unstable stratigraphic samples;

Equipment and measuring instruments to be intact, accurate;

Through repeated tests, the comparative test to improve the test accuracy, but also to adjust the accuracy of the machine can operate;

For the different types of flushing fluid type and performance parameters, the use of comparative tests, orthogonal test and other methods,

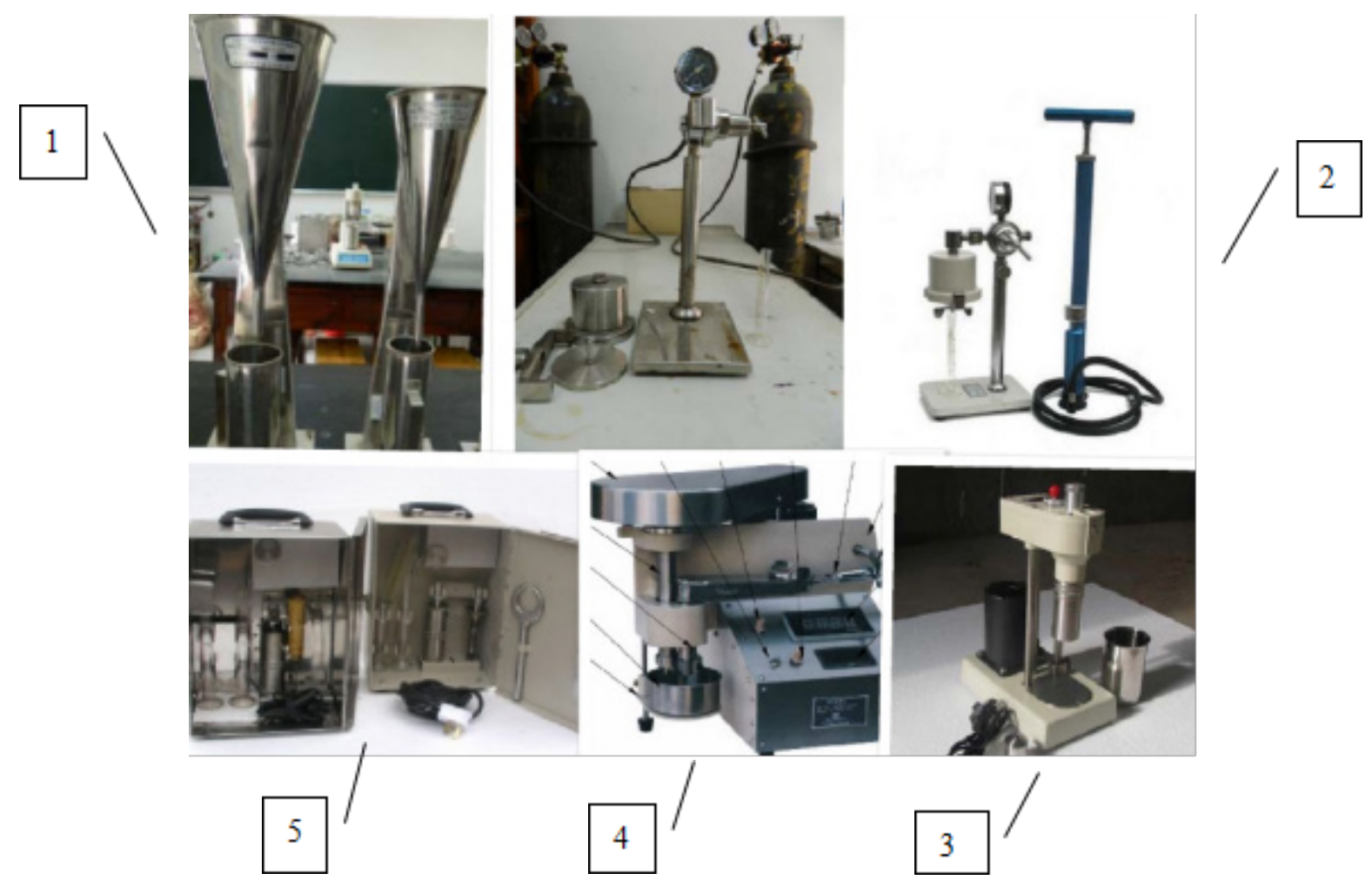

Figure 2 Commonly used equipment: 1, Funnel viscometer, 2, The pressure loss meter, 3, Solid content analyzer, 4, EP-B extreme pressure lubricator, 5, Rotary viscometer 
and cost accounting, write performance in line with design requirements, cost and economic rinse liquid formula.

3.3 Quality control of flushing fluid during drilling construction

3.3.1 Quality control of rinse liquid materials and additive management

(1) All approach materials and additives must be classified, piled up in batches, is strictly prohibited materials mixed. More than the shelf life of the material is strictly prohibited. And do under the pad cover, moisture, rain measures.

(2) Into the pulp material must be regular manufacturers of products, and with product certification. After passing the inspection before entering the field. Regularly on the pulp material for experimental and analysis.

3To establish a material management quality control system, which is a branch system into the overall material management system of drilling engineering, to establish the material management plan, material inspection, daily management and statistics.
3.3.2 Quality control of the rinse cycle system settings

The rinse circulation system is the control of the solid content of the rinse solution during drilling. Commonly used solid phase control of mechanical removal, chemical flocculation, precipitation de-sander. Drilling in a variety of drilling purposes, stratigraphic characteristics, drilling process methods vary widely, the drilling rinse circulation system configuration is very different. In the small input, easy to operate, based on the drilling process to meet the safety and rinse function of the need to configure the rinse circulation system. Such as precipitation desalination, chemical flocculation, mechanical removal, the former method can be resolved, without the latter treatment.

The setting of the rinse circulation system has an important effect on the cycle of the rinse solution. The effective circulation system can control the solid content of the rinse liquid and maintain the flushing liquid performance parameters, thus improving the utilization rate of the flushing fluid and reducing the drilling engineering cost. The quality control of the rinse cycle system is generally started with two points from the system ancillary equipment, the circulation pool and the circulation tank. The specific quality control structure is shown in Figure 3 below.

3.3.3 Quality control of the preparation and maintenance of the rinse solution

(1) According to the design of the rinse liquid rinses liquid preparation. Cannot arbitrarily change the rinse liquid formula, preparation method, subject to the consent of the relevant technical staff can be changed.

(2) In accordance with the design requirements of the rinse liquid rinse liquid performance indicators, timely replenishment of liquid treatment agent to maintain the design of the rinse fluid performance stability.

(3) Combined with the design of the rinse solution preparation program to control the addition of treatment agent, and in accordance with the treatment agent to clearly add the order and manner.

(4) After adding the treatment agent in the mixing, to control the mixing time, to ensure that all kinds of treatment agent can be stirred evenly, the specific time determined by the mud

Quality control of mud circulation system

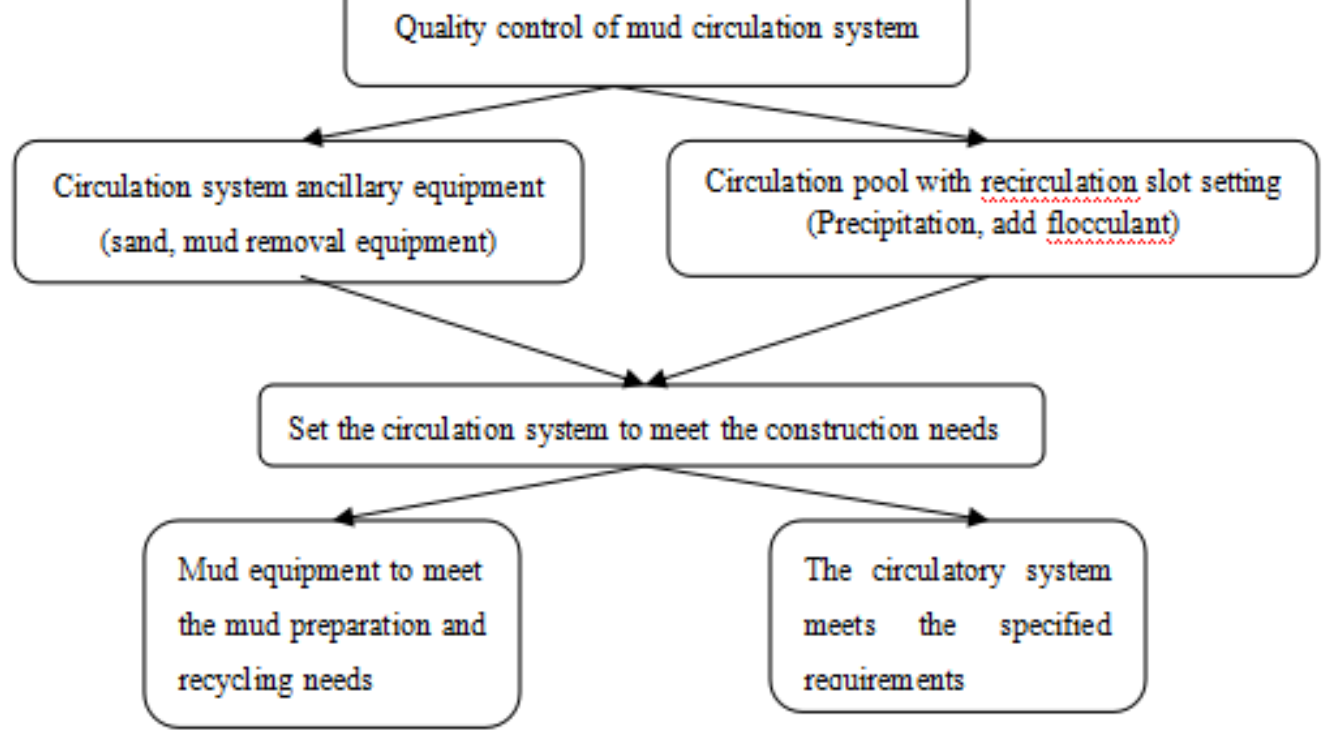

Figure 3 Mud circulation system construction quality control structure diagram 
formula. For similar emergencies such as leakage, can be combined with the actual situation to reduce the mixing time.

(5) According to the different characteristics of drilling into the formation, timely adjust the performance of the rinse solution to meet the needs of drilling in a timely manner.

(6) Regular cleaning cycle tank, regularly cleans up the sedimentation tank. Prevent rain, water into the circulatory system.

(7) When the cement is sealed, the waste mud does not flow into the mud tank, especially the rinse solution containing the organic treatment agent.

\section{Conclusion}

In this paper, the quality control system and the quality of the rinse solution are explored, and the quality control principle, method and requirements of a series of drilling fluid are given. In terms of mine geological core drilling, because of the rope through the core drilling technology popularization application, the machine mainly uses a solid cleaning solution and low solid slurry. Preparation of the application program from the product business, to understand the product variety, there is no more accurate measurement and test equipment, cannot be scientific preparation, control rinse solution, lack of drilling technology consulting market, many aircraft cannot be competent drilling complex. Hope that there is a very intelligent "geological core drilling mud expert system" popularization to the machine, will be on the drilling engineering professional and technical level greatly improved.

\section{References}

[1] Li Xudong. Study on the Importance of Fine Management to Construction Project [J]. Oriental Enterprise Culture .2014 (03)

[2] Hu Jiliang, Tao Shixian. Design Factors and Analysis of Drilling Fluid System in Deep Geological Drilling [J]. Prospecting Engineering (Rock and Soil Drilling and Tunneling) .2011 Vol. 38 , No. 4

[3] Yuan Mingwen, Yao Jianguan. To Improve The Quality of Deep Drilling Core Thinking and Recommendations [J]. Technology Start Monthly. 2015 (07)

[4] Qin Chengchun. Discussion on the Technical Method of Improving the Quality of Deep Drilling Core [J]. Western Exploration Engineering $.2016(01)$

[5] PENG Xu-dong, CHEN Li-yi, HE Yuxin, ZHU Wen-jian. Implementation of Slope Expert System for Drilling Site [J]. Exploration Engineering (Geotechnical Drilling Engineering).

[6] ZHU Heng-yin, CAI Zheng-shui, WANG Qiang, CHENG Hong-wen, ZHANG Zheng. Study and Application of Deep Drilling Technology [J]. Geo- logical Equipment.

[7] Liu Shuquan, Song Dongyong, Zhang Xiaoli, Bao Zhijiang. Application of Abandoned Drilling Fluid and Drilling Technology in Wen 96-11 Well [J]. Natural Gas Technology and Economy .2014 (01)

[8] He Long, Lin Xuanyi, Fang Yongchun, Cheng Shaoyun, Li Jianhua. Oilfield Waste Drilling Fluid Treatment Technology Ideas and Practice [J]. Petroleum and Chemical Equipment $.2013(06)$

[9] Chen Bo, Zheng Jie. Technology and Application of Harmless Treatment of Abandoned Drilling Fluid in Northwestern Sichuan [J]. Inner Mongolia Petrochemical Industry $.2010(17)$

[10] Chen Xiaoying. Waste Drilling Fluid Harmless Treatment and the Environment [J]. Science and Technology Innovation Guide .2009 (21)

[11] Liu Dawei, Bai Juan. Disposal Countermeasures of Drilling Fluid in Loess Zone. 2011

[12] Deng Hongzhang, Wang Yanhua. Study on CMC Method of Synergetic Degradation in Waste Drilling Fluid. 2011

[13] Liu Dawei, Bai Juan. Disposal Countermeasures of Drilling Fluid in Loess Zone.2011

[14] Deng Hongzhang, Wang Yanhua. Study on CMC Method of Synergetic Degradation in Waste Drilling Fluid.2011 